\title{
HOMEOSTASE DO SÓDIO EM CÃES NEFROPATAS SOB INFUSÃO DE DOPAMINA
}

\author{
BRUM, Alexandre Martini ${ }^{1}$ \\ CARVALHO, Marileda Bonafim ${ }^{2}$ \\ PEREIRA, Marcy Lancia ${ }^{3}$
}

Recebido em: 2009-07-26

Aprovado em: 2009-09-10

ISSUE DOI: $10.3738 / 1982.2278 .276$

RESUMO: A dopamina é um composto endógeno amplamente utilizado em terapia intensiva. Possui um amplo espectro de ações, tanto sobre o sistema cardiovascular como urinário. Aumento da taxa de filtração glomerular, do fluxo sangüíneo renal e excreção fracionada de sódio são efeitos renais esperados em indivíduos normais, porém são pouco explorados na medicina veterinária. Com o propósito de avaliar a homeostase do sódio em cães nefropatas, este estudo foi conduzido. Diferentes doses de dopamina foram administradas em cães nefropatas. Avaliações laboratoriais foram realizadas durante e após os tratamentos. O clearance de creatinina e a excreção fracionada de sódio apresentaram aumento dosedependente nos cães sadios. Em cães nefropatas, ambas as dose aumentaram discretamente a TFG, porém não alterou a excreção fracionada de sódio e pressão arterial sistêmica.

Palavras-chave: Dopamina. Canino. Insuficiência renal.

\section{HOMEOSTASIS OF SODIUM IN NEPHROPATHY DOGS UNDER INFUSION OF DOPAMINE}

SUMMARY: Dopamine is an endogenous compound widely used in intensive care. It has a broad spectrum of actions on both cardiovascular and urinary system. Increased glomerular filtration rate, renal blood flow and fractional excretion of sodium are expected renal effects in normal individuals, but are little used in veterinary medicine. With the aim to assess the homeostasis of sodium in nephropathy dogs, this study was conducted. Different doses of dopamine were administered in nephropathy dogs. Laboratory evaluations were performed during and after the treatments. The creatinine clearance and fractional excretion of sodium showed dose-dependent increase in healthy dogs. Nephropathy dogs, both dose slightly increased the GFR, but did not alter the fractional excretion of sodium and blood pressure.

Keywords: Dopamine. Canine. Renal failure

\section{INTRODUÇÃO}

A dopamina é uma catecolamina endógena, precursora imediata da norepinefrina que apresenta a capacidade de estimular diferentes receptores dopaminérgicos e adrenérgicos de forma dose-dependente ( HUSSAIN; LOKHANDWALA, 2003 ). A estimulação dos receptores D1 causa ativação da adenilato ciclase e aumento da

\footnotetext{
${ }^{1}$ Doutorando na UNESP/Jaboticabal, na área de nefrologia de pequenos animais e professor da UNIFRAN, nas disciplinas de Çlínica Médica e Terapêutica de Pequenos Animais e LAboratório Clínico Veterinário. E-mail- alexmbrum@bol.com.br

${ }^{2}$ FCAV-UNESP/Jaboticabal - e-mail: mariledacarvalho@ @cav.unesp.br

${ }^{3}$ FCAV-UNESP/Jaboticabal e-mail: $\underline{\text { mlancia@ yahoo.com.br }}$
} 
concentração intracelular do segundo mensageiro AMPc, induzindo hipotensão e aumento de fluxo sanguíneo para os rins, cérebro, vasos mesentéricos e coronárias, além de diurese e natriurese (LeCLAIR et al, 1998). McDONALD et al (1964) demonstraram que a dopamina aumenta o fluxo sanguíneo renal em humanos por diminuição da resistência vascular renal. Em doses baixas de dopamina, a estimulação de receptores D1 no leito vascular renal induz vasodilatação e aumento do fluxo sanguíneo renal (TOBATA et al, 2004), mas doses altas, capazes de estimular receptores $\alpha$ adrenérgicos, levam a vasoconstrição (FURUKAWA et al, 2002). A ação renal da estimulação D2 ainda é discutida. Embora alguns pesquisadores acreditem que a natriurese deva-se à estimulação simultânea de receptores D1 e D2, vários outros trabalhos mostram que agonistas D2 causam antidiurese e antinatriurese (HUSSAIN; LOKHANDWALA, 2003). Além disso, a estimulação deste receptor contribui para a hiperfiltração induzida por aminoácidos. Apesar do mecanismo exato de ação não estar esclarecido, acredita-se que seja através de estimulação neuronal (LUIPPOLD; MÜHLBAUER, 1998).

Vários mecanismos estão envolvidos na regulação renal do balanço de sódio, entre eles podem ser ressaltados o balanço tubuloglomerular, a aldosterona e angiotensina II. CAREY (2001) relata que aproximadamente 50\% da excreção basal de sódio é controlada pela dopamina. A natriurese é induzida por alterações hemodinâmicas renais e mecanismos tubulares (RAGSDALE et al., 1990). A inibição da bomba $\mathrm{Na}^{+}-\mathrm{K}^{+}$-ATPase e a troca de $\mathrm{Na}^{+}$por $\mathrm{H}^{+}$nos túbulos contorcidos proximais aumentam a EFNa em animais hígidos e euvolêmicos, porém perde este efeito na presença de hipertensão (DEBSKA-SLIZIEN et al, 1994), desidratação ou carga excessiva de sódio (CAREY, 2001). Este aumento na excreção do sódio ocorre por diminuição acentuada da reabsorção tubular no néfron proximal, sem compensação pelo néfron distal (OLSEN et al, 1990). A inibição da reabsorção de sódio deve-se à estimulação do receptor dopaminérgico D1. A ativação da adenilato ciclase via estimulação da proteína $\mathrm{G}$, aumenta a concentração de AMPc intracelular, que por sua vez leva à ativação da PKA, causando fosforilação do cambiador de $\mathrm{Na}^{+} / \mathrm{H}^{+}$e, consequentemente, inibição deste transporte na membrana apical das células tubulares. Há indícios da participação da via AMPc/PKA na inibição da bomba $\mathrm{Na}^{+}, \mathrm{K}^{+}$-ATPase na membrana basolateral das células epiteliais dos túbulos contorcidos proximais e em outras partes dos néfrons. Na inibição desta bomba, a PLC e a PKC têm papéis importantes por causarem a fosforilação da proteína de membrana e perda de sua função 
(HUSSAIN; LOKHANDWALA, 2003). A dopamina apresenta ação parácrina na estimulação dos receptores das células tubulares renais, ou seja, age diretamente na luz tubular, sem influência de ação sistêmica (CAREY, 2001). A ação dos receptores dopaminérgicos D2 sobre a regulação da reabsorção do sódio é controversa. A estimulação conjunta de receptores D1 e D2 nas células epiteliais dos túbulos proximais parece ser necessária para a inibição da atividade da bomba $\mathrm{Na}^{+}-\mathrm{K}^{+}$-ATPase (BERTORELLO; APERIA, 1990), mas o sinergismo parece ocorrer somente em situações de expansão de volume circulante. Estimulação dos receptores D2 não aumenta a natriurese, tendo o quinpirole, um agonista D2 utilizado experimentalmente, ação anti-natriurética (JOSE et al, 1998). A ativação da bomba $\mathrm{Na}^{+}-\mathrm{K}^{+}$-ATPase pode ocorrer por estimulação de receptores D2, devido a diminuição do AMPc intracelular via proteína $G_{i}$, que ativa a tirosina kinase (HUSSAIN; LOKHANDWALA, 1998). Além destes mecanismos diretos sobre a regulação de sódio, a estimulação de receptores D1, via aumento do AMPc intracelular, diminui a expressão dos receptores de angiotensina II nos túbulos contorcidos proximais e, de forma indireta, altera o balanço de sódio (CHENG et al, 1996). A estimulação de receptores $\alpha$-adrenérgicos nos túbulos renais possui ação antagônica aos receptores D1, pois eles estimulam a atividade da bomba de $\mathrm{Na}^{+}-\mathrm{K}^{+}$-ATPase, aumentando a reabsorção renal de sódio (CHEN et al, 1993). Desta forma, fica evidente que a atividade da bomba $\mathrm{Na}^{+}-\mathrm{K}^{+}-$ ATPase, no túbulo contorcido proximal, é determinada pelo balanço entre a estimulação $\alpha$-adrenérgica, aumentando a reabsorção de sódio, e a inibição dopaminérgica, que cursa com aumento da natriurese (IBARRA, et al, 1993)

Disfunção dopaminérgica está descrita em humanos e roedores hipertensos. Defeitos na L-dopa-descarboxilase, enzima que converte a L-dopa em dopamina, e na estimulação de receptores D1 específicos estão envolvidos na patogênese da hipertensão nestas espécies. A deficiência de resposta dopaminérgica, acarreta em diminuição da natriurese, principalmente frente a uma sobrecarga de sódio (HUSSAIN; LOKHANDWALA, 2003). Há poucas informações sobre a participação da disfunção dopaminérgica no desencadeamento da hipertensão em pacientes nefropatas.

\section{MATERIAL E MÉTODOS}

Foram estudados dois grupos de cães, um composto por cinco cães sadios (GS) e o outro por quatro nefropatas (GN). Para a formação dos grupos, os cães foram 
avaliados clínica e laboratorialmente. Coletaram-se amostras de sangue para hemograma e perfil bioquímico sérico e urina. Os cães que não apresentaram alterações na avaliação inicial e cujo valor de clearance de creatinina foi superior a $1,45 \mathrm{~mL} / \mathrm{min} / \mathrm{kg}$, compuseram o GS. Os cães com nefropatia e valores de clearance de creatinina inferiores a $1,45 \mathrm{~mL} / \mathrm{min} / \mathrm{kg}$, azotêmicos ou não e sem outras doenças, compuseram o GN. Estes cães apresentaram doenças renais predominantemente túbulointersticiais, conforme as avaliações laboratoriais.

Protocolo experimental: Os cães dos dois grupos foram submetidos à avaliação basal (controle negativo) e a outras seis avaliações para testar os efeitos de dois protocolos de infusão de dopamina em solução de $\mathrm{NaCl}$ a $0,9 \%$. As avaliações incluíram o controle positivo (durante e 30 minutos após infusão de solução de $\mathrm{NaCl}$ a 0,9\%), o primeiro teste (durante e 30 minutos após infusão de dopamina na dose de $1 \mu \mathrm{g} / \mathrm{kg} / \mathrm{min}$ ) e o segundo teste (durante e 30 minutos após infusão de dopamina na dose de $3 \mu \mathrm{g} / \mathrm{kg} / \mathrm{min}$ ). A solução de $\mathrm{NaCl}$ a $0,9 \%$ foi administrada na taxa de infusão aproximada de $2 \mathrm{~mL} / \mathrm{kg} /$ hora. Para cada um dos testes, a dopamina foi diluída em solução de $\mathrm{NaCl}$ a $0,9 \%$ de modo que fossem obtidas as taxas de infusão do fármaco $(1 \mu \mathrm{g} / \mathrm{kg} / \mathrm{min}$ e $3 \mu \mathrm{g} / \mathrm{kg} / \mathrm{min})$ e mantida a velocidade de administração do solvente ( $2 \mathrm{~mL} / \mathrm{kg} / \mathrm{hora})$. Em cada avaliação foi aferida pressão arterial sistêmica, clearance de creatinina, excreção fracionada, carga filtrada e excreção renal de sódio. Os animais permaneciam na infusão por aproximadamente cem minutos.

Avaliação do clearance de creatinina e excreção fracionada de sódio: A avaliação do clearance de creatinina e excreção fracionada de sódio foi realizada através da técnica de 20 minutos em duplicata, conforme as recomendações feitas por Finco (1995), com modificação feita por Carvalho (1998) que consistiu na exclusão da administração forçada de água.

Avaliação da carga filtrada e excreção renal de sódio: Para estimativa da carga filtrada de eletrólitos, foi realizada dosagem sérica de sódio utilizada na taxa de filtração glomerular em $\mathrm{mL} / \mathrm{min}$, estimada do clearance de creatinina. Para estimativa da excreção renal de sódio, foi utilizada a estimativa de carga filtrada e excreção fracionada de sódio.

Avaliação laboratorial: Foram realizadas dosagens de creatinina e sódio nas soluções e no soro obtidos para avaliação do clearance de creatinina e excreções fracionadas. A creatinina foi dosada pelo método da reação de picrato em meio alcalino, conforme utilizada na urina. As dosagens das concentrações séricas e urinárias de sódio 
foram feitas em aparelho automático de eletrodos íons-seletivos

Avaliação da pressão arterial: A pressão arterial foi obtida por meio de mensuração não-invasiva com aparelho oscilométrico. Foram realizadas cinco determinações e os valores limítrofes superiores e inferiores descartados para a obtenção de uma média mais acurada.

Análise estatística: Os dados obtidos (clearance de creatinina, excreção fracionada de sódio, carga filtrada de sódio, excreção renal de sódio, sódio sérico e valores de pressão arterial sistêmica) foram submetidos à análise de variância seguida pelo teste de Tukey, utilizado para comparação de médias entre os diferentes tratamentos dentro do mesmo grupo. Os dados das sessões um e dois, de cada tratamento, foram submetidos ao teste $t$ pareado. O teste $t$ de Student foi utilizado para comparação de médias, entre grupos, obtidas durante cada tratamento. As análises estatísticas foram realizadas pelo programa de computador SigmaStat for Windows.

\section{RESULTADOS}

Os valores médios de clearance de creatinina $(\mathrm{Ccr})$, excreção fracionada de sódio (EFNa), carga filtrada de sódio ( $\mathrm{CFNa})$, excreção renal de sódio (ExNa) e concentração plasmática de sódio ( $\mathrm{NaS})$ dos cães sadios (GS) e dos nefropatas (GN) estão representados na Tabela 1.

TABELA 1 Médias, desvios padrões e avaliação estatística dos valores clearance de creatinina (Ccr), excreção fracionada $(\mathrm{EFNa})$, carga filtrada $(\mathrm{CFNa})$, excreção renal de sódio (ExNa) e sódio sérico $(\mathrm{NaS})$ obtidos durante $(\mathrm{S} 1)$ e 30 minutos após (S2) infusão de solução de $\mathrm{NaCl} 0,9 \%(\mathrm{NaCl})$ e de dopamina nas taxas de $1 \mu \mathrm{g} / \mathrm{kg} / \mathrm{min}$ (DA 1) e $3 \mu \mathrm{g} / \mathrm{kg} / \mathrm{min}$ (DA 3) em cães sadios e nefropatas.

\begin{tabular}{|c|c|c|c|c|c|c|c|}
\hline \multicolumn{2}{|c|}{ Parâmetros } & \multicolumn{3}{|c|}{ Sadios } & \multicolumn{3}{|c|}{ Nefropatas } \\
\hline & & & $\mathrm{S} 1$ & $\mathrm{~S} 2$ & & S1 & $\mathrm{S} 2$ \\
\hline \multirow{4}{*}{$\underset{\mathrm{mL} / \mathrm{min} / \mathrm{kg}}{\mathrm{Ccr}}$} & Basal & $1,9 \pm 0,2^{\mathrm{a}}$ & & & $1,0 \pm 0,1^{\mathrm{a}}$ & & \\
\hline & $\mathrm{NaCl}$ & & $1,8 \pm 0,2^{\mathrm{Aa}}$ & $1,8 \pm 0,2^{\mathrm{Aa}}$ & & $1,0 \pm 0,3^{\mathrm{Aa}}$ & $0,8 \pm 0,1^{\mathrm{Aa}}$ \\
\hline & DA 1 & & $2,2 \pm 0,4^{\mathrm{Ab}}$ & $1,8 \pm 0,2^{\mathrm{Aa}}$ & & $1,5 \pm 0,4^{\mathrm{Aa}}$ & $1,3 \pm 0,1^{\mathrm{Aa}}$ \\
\hline & DA 3 & & $2,3 \pm 0,2^{\mathrm{Ab}}$ & $1,8 \pm 0,2^{\mathrm{Ba}}$ & & $1,2 \pm 0,1^{\mathrm{Aa}}$ & $1,0 \pm 0,1^{\mathrm{Ba}}$ \\
\hline \multirow{4}{*}{$\begin{array}{c}\mathrm{EFNa} \\
\%\end{array}$} & Basal & $0,7 \pm 0,4^{\mathrm{a}}$ & & & $1,2 \pm 0,2^{\mathrm{a}}$ & & \\
\hline & $\mathrm{NaCl}$ & & $1,2 \pm 0,4^{\mathrm{Aa}}$ & $1,2 \pm 0,2^{\mathrm{Aa}}$ & & $1,5 \pm 0,3^{\mathrm{Aa}}$ & $1,2 \pm 0,2^{\mathrm{Aa}}$ \\
\hline & DA 1 & & $1,3 \pm 0,7^{\mathrm{Aab}}$ & $0,8 \pm 0,3^{\mathrm{Ab}}$ & & $1,2 \pm 0,2^{\mathrm{Aa}}$ & $0,9 \pm 0,2^{\mathrm{Ab}}$ \\
\hline & DA 3 & & $1,7 \pm 0,3^{\mathrm{Ab}}$ & $0,7 \pm 0,4^{\mathrm{Bab}}$ & & $2,0 \pm 0,9^{\mathrm{Aa}}$ & $1,5 \pm 0,8^{\mathrm{Aab}}$ \\
\hline \multirow{4}{*}{$\underset{\mathrm{mEq} / \mathrm{min} / \mathrm{kg}}{\mathrm{CFNa}}$} & Basal & $271,9 \pm 22,8$ & & & $140,5 \pm 14,7^{a}$ & & \\
\hline & $\mathrm{NaCl}$ & & $263,7 \pm 33,9^{\mathrm{Aa}}$ & $268,7 \pm 30,0^{\mathrm{Aa}}$ & & $156,0 \pm 65,7^{\mathrm{Aa}}$ & $133,9 \pm 20,8^{\mathrm{Aa}}$ \\
\hline & DA 1 & & $318,7 \pm 59,4^{\mathrm{Ab}}$ & $267,1 \pm 26,6^{\mathrm{Aa}}$ & & $232,2 \pm 54,1^{\mathrm{Aa}}$ & $194,6 \pm 23,9^{\mathrm{Aa}}$ \\
\hline & DA 3 & & $332,9 \pm 32,7^{\mathrm{Ab}}$ & $263,5 \pm 33,8^{\mathrm{Ba}}$ & & $191,7 \pm 24,2^{\mathrm{Aa}}$ & $158,6 \pm 32,6^{\mathrm{Ba}}$ \\
\hline
\end{tabular}


TABELA 1 Médias, desvios padrões e avaliação estatística dos valores clearance de creatinina (Ccr), excreção fracionada $(\mathrm{EFNa})$, carga filtrada $(\mathrm{CFNa})$, excreção renal de sódio (ExNa) e sódio sérico (NaS) obtidos durante (S1) e 30 minutos após (S2) infusão de solução de $\mathrm{NaCl} 0,9 \%(\mathrm{NaCl})$ e de dopamina nas taxas de $1 \mu \mathrm{g} / \mathrm{kg} / \mathrm{min}$ (DA 1) e $3 \mu \mathrm{g} / \mathrm{kg} / \mathrm{min}$ (DA 3) em cães sadios e nefropatas.

(Conclusão)

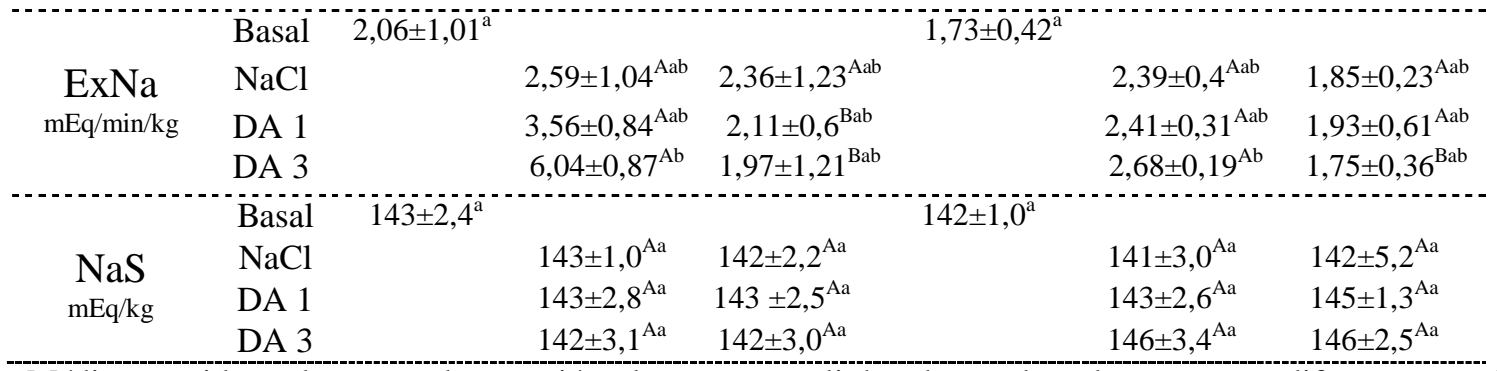

Médias seguidas pela mesma letra maiúscula, na mesma linha, dentro de cada grupo, não diferem entre si pelo teste de $t$ de Student.

Médias seguida pelo menos por uma mesma letra minúscula, na mesma coluna, dentro de cada parâmetro, não diferem entre si pelo teste de Tukey.

Clearance de Creatinina: Aumentou significativamente $(p \leq 0,05)$ nas infusões de ambas doses de dopamina nos animais normais (Tabela 1 e Figura 1). Nos nefropatas, determinou aumento do Ccr, porém sem significância (Tabela 1 e Figura 2).

Excreção fracionada de sódio: A infusão de dopamina determinou aumento $(\mathrm{p} \leq 0,05)$ da EFNa nos cães normais, quando comparada a resposta à dose de $3 \mu \mathrm{g} / \mathrm{kg} / \mathrm{min}$ com o basal e controle positivo e na dose de $1 \mu \mathrm{g} / \mathrm{kg} / \mathrm{min}$ quando comparada com o basal. Não houve diferença significativa entre as duas doses de dopamina. Depois da infusão de dopamina, a EFNa diminuiu, tanto em relação aos valores obtidos durante a infusão como em relação ao valor do controle, atingindo significância $(p \leq 0,05)$ na dose de $3 \mu \mathrm{g} / \mathrm{kg} / \mathrm{min}$ (Tabela 1 e Figura 1). Nos nefropatas, não houve diferença entre as médias obtidas durante as infusões. As médias observadas no período pós-infusão diminuíram ligeiramente, porém não houve significância (Tabela 1 e Figura 2).

Carga filtrada de sódio: A infusão de dopamina, em ambas as doses, determinou aumento significativo $(\mathrm{p} \leq 0,05)$ da carga filtrada de sódio dos cães normais. No período pós-infusão, os valores de CFNa retornaram a valores próximos aos basais (Tabela 1 e Figura 1). Nos cães nefropatas, a carga de sódio filtrada aumentou durante as infusões de dopamina, com redução dos valores após o término da infusão, porém só ocorreu significância $(\mathrm{p} \leq 0,05)$ na dose de $3 \mu \mathrm{g} / \mathrm{kg} / \mathrm{min}$ (Tabela 1 e Figura 2).

Excreção renal de sódio: A infusão de dopamina na dose de $3 \mu \mathrm{g} / \mathrm{kg} / \mathrm{min}$ determinou aumento significativo $(\mathrm{p} \leq 0,05)$ da excreção renal de sódio dos cães normais. No período pós-infusão, os valores de ExNa retornaram a valores próximos aos basais, 
diferindo significativamente do período de tratamento durante ambas infusões de dopamina $(\mathrm{p} \leq 0,05)$ (Tabela 1 e Figura 1). A excreção renal de sódio no nefropatas apresentou aumento significativo $(\mathrm{p} \leq 0,05)$ durante ambas infusões de dopamina. Assim como nos cães sadios, os valores retornaram próximos aos basais, apresentando redução significativa $(\mathrm{p} \leq 0,05)$ somente após a infusão da dose de $3 \mu \mathrm{g} / \mathrm{kg} / \mathrm{min}$ (Tabela 1 e Figura 2).


Figura 1 -Representações gráficas das médias dos valores e erro padrão do, clearance de creatinina (Ccr), excreção fracionada de sódio (EFNa), excreção renal de sódio (ExNa), carga filtrada de sódio (CFNa) obtidos durante (1) e 30 minutos após (2) infusão de solução de $\mathrm{NaCl}$ 0,9\% e de dopamina, nas taxas de $1 \mu \mathrm{g} / \mathrm{kg} / \mathrm{min}$ (DA1) e $3 \mu \mathrm{g} / \mathrm{kg} / \mathrm{min}$ (DA3) em cães sadios.

Concentração sérica de sódio: Tanto nos cães sadios como nefropatas, a concentração sérica de sódio não apresentou variações significativas durante os tratamentos ou entre os grupos.

Pressão Arterial Sistêmica: As pressões arteriais sistólica não apresentaram alterações significativas durante as infusões ou na comparação entre grupos. 

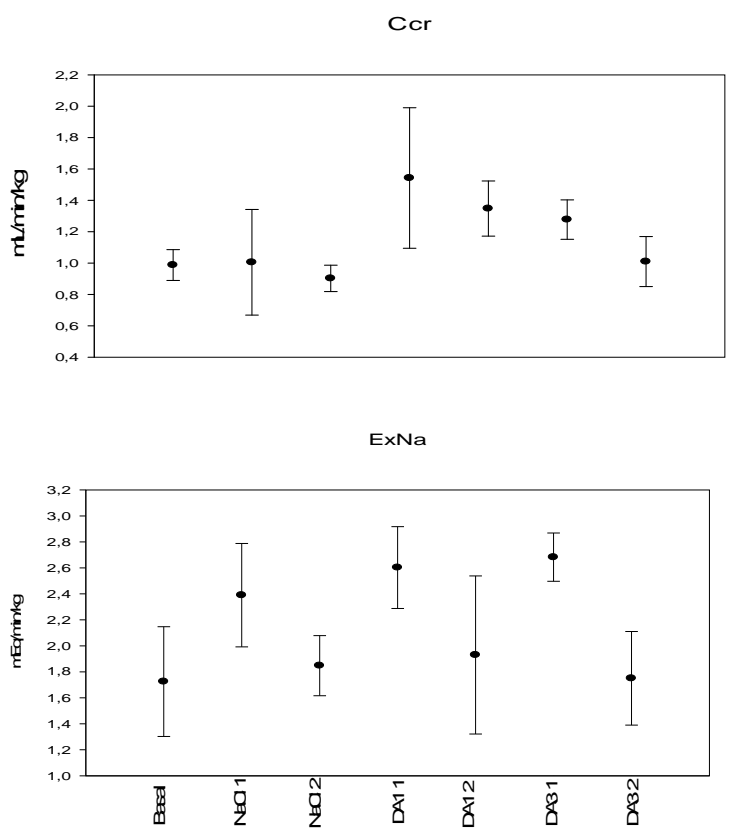
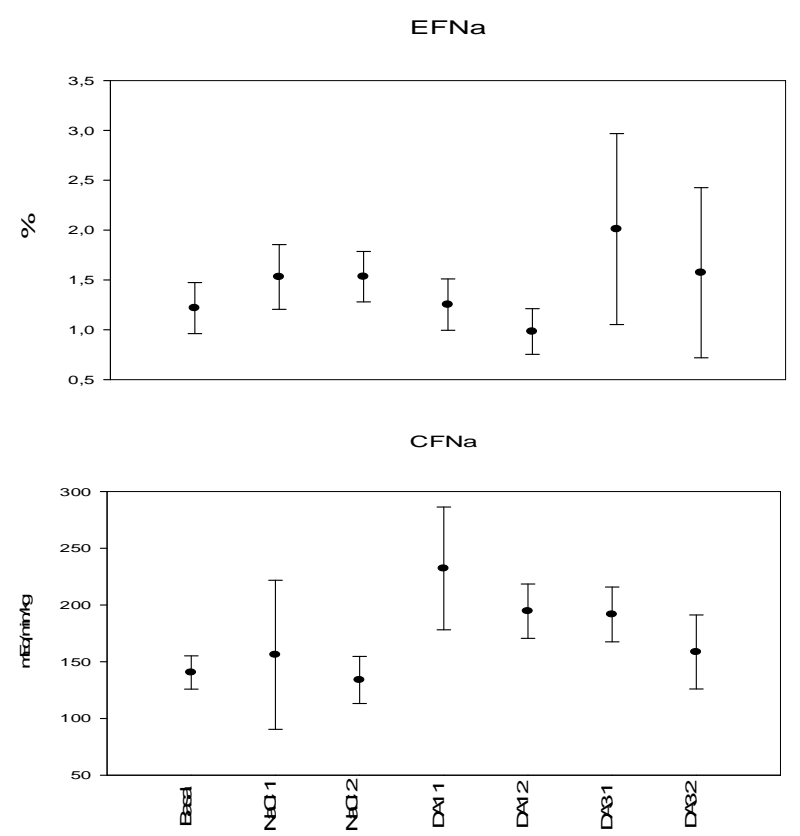

Figura 2 -Representações gráficas das médias dos valores e erro padrão do clearance de creatinina $(\mathrm{Ccr})$, excreção fracionada de sódio $(\mathrm{EFNa})$, excreção renal de sódio $(\mathrm{ExNa})$ e carga filtrada de sódio (CFNa) obtidos durante (1) e 30 minutos após (2) infusão de solução de $\mathrm{NaCl}$ $0,9 \%$ e de dopamina, nas taxas de $1 \mu \mathrm{g} / \mathrm{kg} / \mathrm{min}$ (DA1) e $3 \mu \mathrm{g} / \mathrm{kg} / \mathrm{min}$ (DA3) em cães nefropatas.

\section{DISCUSSÃO}

O presente estudo demonstrou que a dopamina apresenta ações natriuréticas em cães normais e nefropatas. Estas ações renais da dopamina já foram descritas por McDonald et al (1964) em humanos e por McNay et al (1969) em cães saudáveis.

Nos cães sadios, a excreção fracionada de sódio aumentou, de forma dosedependente. O mesmo foi observado em humanos por Olsen et al (1990), que evidenciaram um potencial natriurético maior com a dose de $3 \mu \mathrm{g} / \mathrm{kg} / \mathrm{min}$. Nos cães nefropatas, a dose de $1 \mu \mathrm{g} / \mathrm{kg} / \mathrm{min}$ não induziu aumento da EFNa. Este efeito natriurético foi observado somente na dose de $3 \mu \mathrm{g} / \mathrm{kg} / \mathrm{min}$. Segundo CAREY (2001), os compostos dopaminérgicos são extremamente importantes na excreção renal de sódio, sendo responsáveis por aproximadamente $50 \%$ da excreção basal. A natriurese é induzida pela inibição do transporte de $\mathrm{Na}^{+} / \mathrm{H}^{+}$e $\mathrm{NaPi}$ tipo II, além da bomba de $\mathrm{Na}^{+}-\mathrm{K}^{+}$ATPase (RAGSDALE et al, 1990; DEBSKA-SLIZIEN et al, 1994). A dopamina é uma catecolamina de ação parácrina nas células tubulares renais (HUSSAIN; LOKHANDWALA, 2003). Havendo aumento de fluxo tubular, a dopamina pode ficar menos disponível para sua ação inibitória sobre o transporte de $\mathrm{Na}^{+} / \mathrm{H}^{+}$e a bomba de 
$\mathrm{Na}^{+}-\mathrm{K}^{+}$ATPase. Se o fluxo permitisse maior interação da dopamina com seus receptores, haveria acréscimo mais significativo da $\mathrm{EFNa}$, pois os diversos transportes de sódio seriam inibidos mais intensamente. De fato, a administração de dopamina na dose de $3 \mu \mathrm{g} / \mathrm{kg} / \mathrm{min}$ parece ter aumentado a oferta da substância, favorecendo a ligação com seus receptores, que resultou em aumento da EFNa.

Outro possível fator importante relacionado a natriurese é a atenuação da resposta renal à angiotensina II, conforme descrito por Barnett et al (1986). O antagonismo foi descrito no glomérulo e células mesangeais de roedores, mas também podem estar envolvidos na natriurese, uma vez que esta substância apresenta importante papel natriurético.

A densidade de receptores D1 é maior nos túbulos contorcidos proximais do que nos vasos do parênquima renal, justificando a ocorrência da natriurese em doses inferiores às que alteram a hemodinâmica renal (LOKHANDWALA; AMENTA, 1991). Isto não foi observado nos cães nefropatas, nos quais o aumento da TFG foi evidenciando ante do aumento na EFNa. Roedores hipertensos apresentam resposta deficiente à estimulação dopaminérgica nas células dos túbulos contorcidos proximais (CHEN et al, 1993), porém sob infusão de dopamina, pacientes com hipertensão essencial apresentam resposta natriurética (ANDREJAK; HARY, 1986), sugerindo que os receptores dopaminérgicos localizados na porção distal do néfron estão sobre expressados (O’CONNELL et al, 1997). O incremento na dose de dopamina, neste caso $3 \mu \mathrm{g} / \mathrm{kg} / \mathrm{min}$, tornaria esta catecolamina mais disponível nas porções finais do néfron, ocasionando um aumento na EFNa e ExNa, quando uma possível disfunção dopaminérgica está presente nos células tubulares proximais.

A menor resposta natriurética, evidenciada nos cães nefropatas, pode decorrer de uma resposta dopaminérgica deficiente. Em roedores com hipertensão espontânea, frente à estimulação com agonistas dopaminérgicos, a natriurese é reduzida, enquanto o controle sobre a reabsorção do fosfato é mantido normal (DEBSKA-SLIZIEN et al, 1994). O mecanismo envolvido nesta resposta dopaminérgica deficiente está relacionado aos receptores D1 acoplados à PLC, acarretando em falha da inibição da bomba de $\mathrm{Na}^{+}-\mathrm{K}^{+}$ATPase nos túbulos contorcidos proximais (CHEN et al, 1993).

Nos cães sadios, o aumento da carga filtrada de sódio, durante a infusão de ambas doses de dopamina, ocorreu pelo aumento na TFG, evidenciado neste estudo e descrito por McNay et al (1969) em cães sadios, pois este parâmetro está diretamente relacionado ao clearance de creatinina. Apesar do pequeno aumento do Ccr nos cães 
nefropatas, este não foi suficiente para aumentar significativamente a CFNa nestes pacientes. Em relação à excreção renal de sódio, os cães sadios apresentaram aumento de $293 \%$ durante a infusão de dopamina na dose de $3 \mu \mathrm{g} / \mathrm{kg} / \mathrm{min}$, enquanto o aumento, nos cães nefropatas, foi de $154 \%$ durante a infusão da mesma dose. O aumento de excreção renal de sódio, durante a infusão de dopamina, deve-se pelo aumento da TFG e inibição da reabsorção renal de sódio. O aumento da TFG, conforme descrito por McDonald et al (1964), aumenta a quantidade de sódio presente no filtrado glomerular. O aumento do fluxo tubular associado à carga filtrada de sódio maior, diminui a reabsorção renal de sódio devido ao fenômeno de arrastamento. Além disso, esta dose de dopamina apresenta maior potencial natriurético (OLSEN et al, 1990), devido a inibição do transporte de $\mathrm{Na}^{+} / \mathrm{H}^{+}$e $\mathrm{NaPi}$ tipo II, além da bomba de $\mathrm{Na}^{+}-$ $\mathrm{K}^{+}$ATPase (RAGSDALE et al, 1990; DEBSKA-SLIZIEN et al, 1994). A diferença no incremento da ExNa, entre cães sadios e nefropatas, pode estar relacionada à menor capacidade da dopamina de aumentar a TFG nos cães nefropatas, além da resposta natriurética deficiente. Disfunções dopaminérgicas estão descritas em pacientes hipertensos. Nestes, a resposta deficiente à dopamina, cursa com diminuição da excreção renal de sódio (HUSSAIN; LOKHANDWALA, 2003). A avaliação da função dopaminérgica não está bem descrita em pacientes nefropatas. A resposta deficiente à estimulação dopaminérgica, evidenciada nos cães nefropatas neste estudo, pode estar envolvida na gênese da hipertensão. É importante ressaltar que todos os cães nefropatas deste estudo apresentavam doenças predominantemente túbulo-intersticiais.

Como os receptores D1 estão presentes em grande quantidade nos túbulos contorcidos proximais (LOKHANDWALA; AMENTA, 1991), não só uma disfunção nos receptores, mas como também uma diminuição na população das células tubulares podem estar envolvidas na resposta dopaminérgica dos pacientes nefropatas.

A dopamina apresenta ação diurética e natriurética em cães sadios e nefropatas. A ação dopaminérgica sobre as funções renais de cães resulta da combinação de mecanismos glomerulares e túbulo-intersticiais em indivíduos sadios. Contudo, nos indivíduos com nefropatias crônicas, independentemente da dose administrada, as alterações renais existentes limitam os tipos e intensidade das respostas. Nos cães nefropatas, a infusão de dopamina, em ambas as doses, não alteraram a excreção fracionada de sódio, apesar de aumento discreto na ExNa, evidenciando uma resposta deficiente na natriurese induzida pela estimulação dopaminérgica em cães nefropatas. 


\section{REFERÊNCIAS}

ANDREJAK, M., HARY, L. Enhanced dopamine renal responsiveness in patients with hypertension. Clin Pharmacol Ther. v. 40, p. 610-614, 1986

BARNETT, R. et al. Dopamine Attenuates the contractile response to angiotensin II in isolated rat glomeruli and cultured mesangial cells. Circul. Res., v. 59, p.529-533, 1986.

BERTORELLO, A.; APERIA, A. Inhibition of proximal tubule $\mathrm{Na}^{+}, \mathrm{K}^{+}$-ATPase activity requires simultaneous activation of DA1 e DA2 receptors. Am J Physiol Renal Fluid Electrolyte Physiol. v. 259, p.924-928, 1990.

CAREY, R. M. Renal dopamine system: paracrine regulator of sodium homeostasis and blood pressure. Hipertension. v. 38, p. 297-302, 2001.

CARVALHO, M. B. et al. Métodos para avaliação de clearance de creatinina exógena em cães: estudo desenvolvido pelo grupo de pesquisa de nefrologia e urologia da FCAV - Unesp, Campus de Jaboticabal. Jaboticabal, 1998. (Não publicado).

CHEN, C.; BEACH, R. E.; LOKHANDWALA, M. F. Dopamine fails to inhibit renal tubular sodium pump in hypertensive rats. Hypertension. v. 21, p. 364-372, 1993.

CHENG, H. F.; BECKER, B. N.; HARRIS, R. C. Dopamine Decreases expression of type-1 angiotensin II receptors in renal proximal tubule. J Clin Invest. v. 97, n. 12, p. 2745-2752, 1996.

DEBSKA-SLIZIEN, A.; H. O. P.; DRANGOVA, R.; BAINES, A.D. Endogenous Dopamine regulates phosphate reabsorption but not NaK-ATPase in spontaneously hypertensive rat kidneys. J Am Soc Nephrol. v. 5, p. 1125-1132, 1994.

FINCO, D. R. Evaluation of renal functions. In: OSBORNE, C. A.; FINCO, D. R. Canine and feline nephrology and urology. Baltimore: Williams e Wilkins, 1995, p.29-46.

FURUKAWA, S. et al. Effects of Dopamine infusion on cardiac and renal blood flows in dogs. J. Vet. Med. Sci. v. 64, n. 1, p.41-44, 2002.

HUSSAIN, T.; LOKHANDWALA, M. F. Renal Dopamine receptor function in hypertension. Hypertension. v. 32, p. 187-197, 1998.

HUSSAIN, T.; LOKHANDWALA, M. F. Renal Dopamine Receptor and Hypertension. Exp Biol Med. v. 228, p. 134-142, 2003.

IBARRA, F. et al. Bidirectional regulation of Na-K-ATPase activity by Dopamine and a-adrenergic agonist. Proc Natl Acad Sci USA. v. 93, p.21-24, 1993. 
JOSE, P. A. et al. Effects of costimulation of Dopamine D1- and D2-like receptors on renal function. Am J Physiol (Regulatory Integrative Comp Phyiol). v. 275, p.986994, 1998.

LeCLAIR, M. M.; BERNDT, T. J.; KNOX, F. G. Effects of renal interstitial infusion of L-dopa on sodium and phosphate excretions. J Labor Clin Med. v. 132, n. 4, p. 308$312,1998$.

LUIPPOLD, G.; MÜHLBAUER, B. Dopamine D2 receptors mediate glomerular hyperfiltration due to amino acids. J Pharmac Exp Therap. v. 286, p. 1248-1252, 1998.

LOKHANDWALA, M. F.; AMENTA, F. Anatomical distribution and function of Dopamine receptors in the kidney. FASEB J. v. 5, p. 3023-3030, 1991

McDONALD, R. H. et al. Effects of Dopamine in man: augmentation of sodium excretion, glomerular filtration rate, and renal plasma flow. J. Clin Invest. v. 43, n. 6, p. 1116-1124, 1964.

McNAY, J. L.; McDONALD, R. H.; GOLDBERG, L. I. Direct renal vasodilatation produced by Dopamine in the dog. Circul. Res. v. 26, p. 510-517, 1965.

O’CONNELL, D. P. et al. Differential human tubular responses to dopamine type 1 receptor stimulation are determined by blood pressure status. Hypertension. v. 29, p. $115-122,1997$

OLSEN, N. V. et al. Renal tubular reabsorption of sodium and water during infusion of low-dose dopamine in normal man. Clin Sci (Lond). v. 78, n. 5, p.503-507, 1990.

RASGADLE, N. V.; LYND, M.; CHEVALIER, L. A. et al. Seletive peripheral dopamine-1 receptor stimulation. Differential responses to sodium loading and depletion in humans. Hypertension. v. 15, p. 914-921, 1990.

TOBATA, D. et al. Effects of Dopamine, dobutamine, amrinone and milrinone on regional blood flow in isoflurane anesthetized dogs. J. Vet. Med. Sci. v. 66, n. 9, p. 1097-1105, 2004. 